\title{
Pemanfaatan Aplikasi Pendeteksi Warna Pakaian Berbasis Android bagi Penyandang Tunanetra di SLB Yukartuni Makassar
}

\section{Bayu Adrian Ashad*1, Ramdaniah², Sriwijanaka3 ${ }^{3}$, St. Hajrah Mansyur ${ }^{4}$}

\author{
1,3Teknik Elektro, Fakultas Teknik, Universitas Muslim Indonesia, Indonesia \\ 2,4Teknik Informatika, Fakultas Ilmu Komputer, Universitas Muslim Indonesia, Indonesia \\ *e-mail: bayuadrianashad@umi.ac.id ${ }^{1}{ }_{\text {ramdaniah@umi.ac.id }}^{2}{ }_{2}$ wijanaka2510@gmail.com $^{3}{ }_{2}$ \\ hajrah.mansyur@umi.ac.id ${ }^{4}$
}

\begin{abstract}
Abstrak
SLB Yayasan Usaha Karya Tunanetra Indonesia (Yukartuni) merupakan sekolah luar biasa yang berlokasi di Makassar, Sulawesi Selatan. Sebagian besar guru dan siswa pada sekolah tersebut adalah penyandang tunanetra. Guru dan siswa penyandang tunanetra mengalami kesulitan dalam memilih warna pakaian yang akan dikenakan di sekolah. Keterbatasan yang dimilikinya seringkali menyebabkan guru dan siswa keliru dalam menggunakan seragam ke sekolah. Dalam memilih pakaian, penyandang tunanetra sangat bergantung pada bantuan orang lain jika akan memilih seragam sekolah. Namun guru dan siswa juga perlu memilih pakaian secara mandiri sehingga tidak perlu bergantung pada orang lain. Pengabdian ini bertujuan untuk memberikan kontribusi kepada masyarakat khususnya di SLB Yukartuni Makassar dengan cara memperkenalkan aplikasi pendeteksi warna pakaian berbasis android. Pengabdian yang dilakukan terdiri dari dua tahap yaitu tahap pembuatan aplikasi dan tahap sosialisasi penggunaan aplikasi. Tahap pertama merupakan tahap pembuatan aplikasi berbasis android berdasarkan hasil observasi masalah yang dihadapi oleh guru dan siswa. Tahap kedua merupakan tahap sosialisasi cara mengoperasikan aplikasi pendeteksi warna pakaian berbasis android. Hasil kegiatan pengabdian menunjukkan bahwa guru dan siswa mampu mengoperasikan aplikasi dengan baik. Selain itu, hasil pengabdian menunjukkan bahwa aplikasi pendeteksi warna pakaian dapat membantu penyandang tunanetra dalam memilih pakaian yang akan digunakan.
\end{abstract}

Kata kunci: Android, Aplikasi, Deteksi Warna Pakaian, Tunanetra

\begin{abstract}
SLB Yayasan Usaha Karya Tunanetra Indonesia (Yukartuni) is a school for students with special needs located in Makassar, South Sulawesi. The majority of teachers and students in the school are blind. Teachers and students with visual impairments have difficulty choosing the color of clothes to wear at school. Its limitations often cause teachers and students to mistakenly wear uniforms to school. In choosing clothes, blind people rely heavily on other people's help when choosing school uniforms. However, teachers and students also need to choose clothes independently so they don't have to depend on others. This service aims to contribute to the community, especially at SLB Yukartuni Makassar by introducing an Android-based clothing color detection application. The service carried out consists of two stages, namely the stage of creating the application and the stage of socializing the use of the application. The first stage is the stage of creating android-based applications based on the results of observations of problems faced by teachers and students. The first stage is the stage of making android-based applications based on the results of observations of problems faced by teachers and students. The second stage is the socialization stage on how to operate an android-based clothing color detection application. The results of the community service show that the teachers and students who are able to operate the application properly. In addition, the results of the community service show that the clothing color detection application can help blind people in choosing the clothes to wear.
\end{abstract}

Keywords: Android, Application, Blind, Clothes Color Detection

\section{PENDAHULUAN}

Tunanetra merupakan kondisi pada seseorang yang mengalami gangguan pada fungsi indera penglihatan. Keadaan tersebut menyebabkan seseorang tidak dapat melihat suatu objek sehingga dapat menghambat aktivitas seseorang dalam mengenali objek atau berkomunikasi dengan orang lain di lingkungannya (Jafar dkk., 2018). 
Dalam mendapatkan informasi, penyandang tunanetra membutuhkan beberapa aspek yaitu visual, suara, dan perabaan. Ketiga aspek tersebut sangat dibutuhkan dalam mendapatkan informasi, pembelajaran, atau pengetahuan. Namun keterbatasan dalam melihat menyebabkan penyandang tunanetra mengandalkan indera pendengaran dan peraba. Indera pendengaran dapat dimaksimalkan melalui audio, sedangkan indera perabaan dapat dimaksimalkan melalui benda konkrit atau media pembelajaran tiruan (Indriastuti \& Saksono, 2018).

SLB Yayasan Usaha Karya Tunanetra Indonesia (Yukartuni) adalah sekolah luar biasa yang terletak di JL. Amd, No. 4, Tamangapa, Pisang Utara, Makassar, Kota Makassar, Sulawesi Selatan. Sekolah tersebut terdiri dari siswa penyandang disabilitas meliputi tunanetra, tunarunggu, tunagrahita. Beberapa guru pada sekolah tersebut juga merupakan penyandang tunanetra. Pada umumnya mahasiswa dan guru berangkat ke sekolah setiap hari senin sampai dengan sabtu menggunakan seragam yang telah ditentukan namun tidak sedikit dari mereka salah menggunakan seragam karena kemampuan mereka yang sulit membedakan warna dan hanya mengandalkan indera penciuman dan indera peraba. Hal tersebut tentu kurang efisien terutama jika guru atau siswa harus memilih pakaiannya sendiri. Siswa dan guru seringkali salah menggunakan kostum. Sehingga dibutuhkan sarana untuk membantu siswa dan guru dalam memilih pakaian berdasarkan identifikasi warna sehingga siswa dan guru dapat memilih dan mengenakan pakaian secara mandiri.

Pada tahun 2018 terdapat penelitian tentang pengenalan warna berbasis android, aplikasi yang dikembangankan merupakan aplikasi berbasis android yang mampu mengidentifikasi 9 jenis warna. Namun objek yang akan dideteksi harus di foto terlebih dahulu agar dapat diproses di sistem. Output dari aplikasi tersebut adalah tulisan berupa warna yang berhasil diidentifikasi (Kurniawan \& Retnowati, 2018). Pada tahun 2019 penelitian serupa juga telah dilakukan dengan menciptakan aplikasi CODA (Color Detector for Blind). Aplikasi yang diciptakan merupakan aplikasi berbasis android dan output berupa audio yang menyebutkan warna objek yang terdeksi. Peneliti mengidentifikasi warna pada 5 objek yang berbeda dan hasil akhir dari penelitian tersebut yaitu penyandang tunanetra dapat menggunakan aplikasi CODA dengan persentasi 73,96\% (Maslahah \& Suharmini, 2019). Penelitian serupa juga telah dilakukan dimana aplikasi yang dikembangkan merupakan aplikasi berbasis android dan menggunakan kamera serta mendeteksi warna secara realtime. Namun aplikasi tersebut dikhususkan sebagai aplikasi uji buta warna dengan menggunakan 20 sampel warna yang berbeda (Mukmin dkk., 2019).

Berdasarkan penelitian sebelumnya, dapat diketahui bahwa aplikasi untuk mendeteksi warna telah diciptakan. Namun obyek yang digunakan merupakan obyek yang berbeda-beda. Selain itu warna yang dapat dideteksi juga masih terbatas sehingga perlu dikembangkan aplikasi untuk mendeteksi warna pakaian berbasis android yang dapat mendeteksi banyak warna serta memberikan kemudahan bagi penyandang tunanetra dalam mengoperasikan aplikasi tersebut. Adapun output dari aplikasi yaitu berupa audio yang menyebutkan warna pakaian yang terdeteksi. Penggunaan audio atau suara merupakan cara yang dapat mempermudah penyandang tunanetra dalam mendapatkan informasi dari aplikasi (Ellia Nurazizah dkk, 2017).

Dengan demikian, pengabdian yang dilakukan terdiri dari dua tahap. Tahap pertama merupakan tahap pengembangan aplikasi pendeteksi warna pakaian berbasis android dengan output berupa suara, sedangkan tahap kedua merupakan tahap sosialisasi pemanfaatan aplikasi tersebut kepada guru dan penyandang tunanetra. Pengabdian dilakukan di SLB Yukartuni Makassar dengan melibatkan dosen dan mahasiswa dalam melakukan kegiatan sosialisasi.

\section{METODE}

Kegiatan pengabdian dilakukan selama 2 bulan dimulai pada 1 November 2021 sampai dengan 11 Desember 2021. Tim pelaksana kegiatan terdiri 6 orang, yaitu 4 orang dosen dan 2 orang mahasiswa yang berasal dari program studi Teknik Informatika dan Teknik Elektro. Kegiatan pengabdian yang dilakukan dari beberapa tahap antara lain:

a. Tahap pertama, merupakan tahap pengembangan aplikasi pendeteksi warna pakaian berbasis android. Dalam mengembangkan aplikasi, dilakukan Langkah awal yaitu melakukan observasi 
ke lokasi SLB Yukartuni Makassar dalam rangka menjalin hubungan mitra dan mengidentifikasi kebutuhan mitra. Setelah itu dilakukan perancangan aplikasi dan pembuatan aplikasi berdasarkan kebutuhan mitra. Tahap pertama dilakukan selama 6 pekan.

b. Tahap kedua, merupakan tahap sosialisi pemanfaatan aplikasi. Tahap kedua merupakan tahap yang dilakukan setelah membuat aplikasi dimana tahap kedua merupakan bentuk implementasi aplikasi dan sosialisasi cara mengoperasikan aplikasi kepada guru dan siswa penyandang tunanetra. Tahap kedua dilakukan selama 1 hari dan 1 kali pertemuan. Adapun jumlah peserta penyandang tunanetra yang mengikuti kegiatan sosialisasi yaitu 15 orang yang terdiri dari 3 orang guru dan 12 orang siswa tingkat Sekolah Menengah Atas (SMA). Pada tahap sosialisasi, dilakukan pengenalan aplikasi, penggunaan aplikasi, dan diskusi agar dapat mengetahui kritik dan saran dari mitra dalam rangka membantu menyelesaikan kebutuhan mitra selanjutnya dibidang teknologi. Selain itu pada tahap sosialisasi, juga dilakukan kegiatan evaluasi untuk mengetahui jumlah guru dan siswa yang dapat menggunakan aplikasi dengan baik.

\section{HASIL DAN PEMBAHASAN}

Kegiatan pengabdian kepada masyarakat yang telah dilakukan merupakan implementasi ilmu pengetahuan dibidang teknologi. Pada tahap pertama dilakukan pembuatan aplikasi berdasarkan hasil observasi kebutuhan mitra. Gambar 1 merupakan tampilan aplikasi sedangkan Gambar 2 merupakan contoh identifikasi warna pada aplikasi.

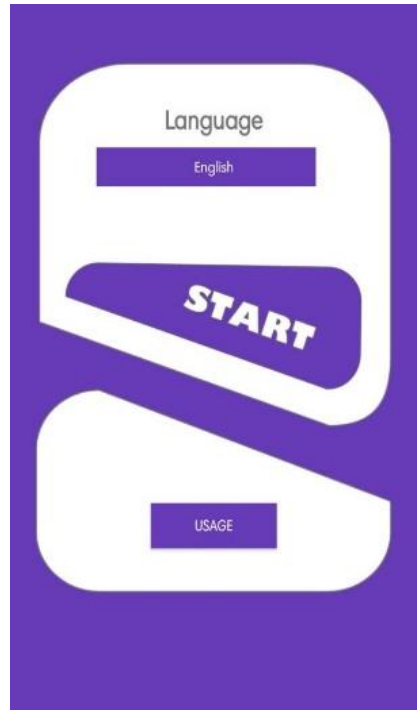

(a)

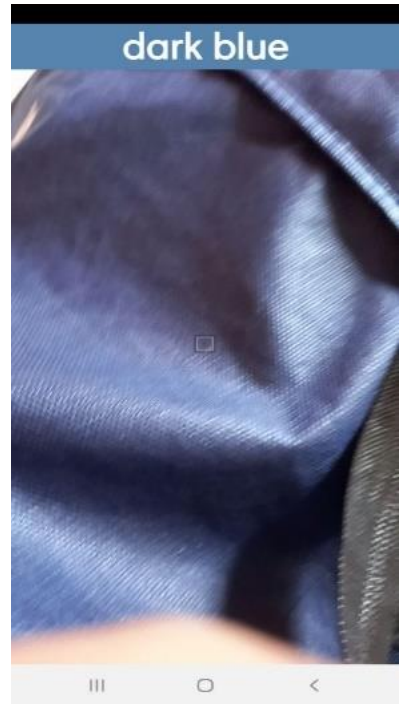

(b)

Gambar 1. Tampilan (a) awal aplikasi dan (b) tampilan halaman utama

Aplikasi yang dikembangkan merupakan aplikasi berbasis mobile dan dapat berfungsi dengan baik dengan menggunakan atau tanpa menggunakan fasilitas Talkback pada handphone. Ketika aplikasi dijalankan dan dimulai dengan menekan tombol start, maka kamera belakang pada handphone akan aktif secara otomatis. Jika ingin menyalakan lampu kilat (Blitz) pada handphone, pengguna dapat mengaktifkannya dengan menekan layar sebanyak 2 kali.

Gambar 2 merupakan tampilan aplikasi dalam mendeteksi warna pakaian. Aplikasi bekerja dengan cara mengambil gambar pakaian secara realtime melalui kamera pada handphone, selanjutnya warna pakaian akan muncul secara otomatis dan warna pakaian akan muncul dilayar handphone serta audio yang menyebutkan warna pakaian akan terputar secara otomatis. Tahap kedua dari kegiatan pengabdian yaitu tahap sosialisasi pemanfaatan aplikasi pendeteksi warna pakaian berbasis android. Gambar 3 merupakan dokumentasi kegiatan pengabdian kepada masyarakat. 


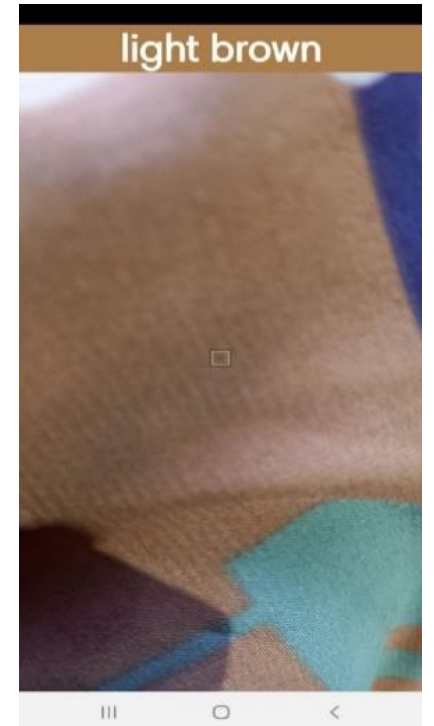

(a)

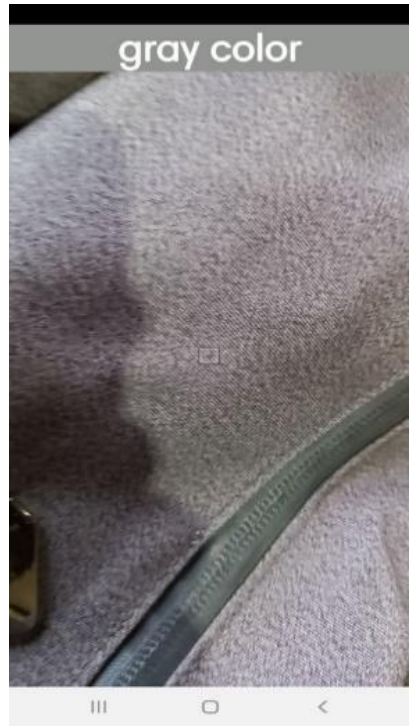

(b)

Gambar 2. Tampilan deteksi warna pakaian (a) coklat muda dan (b) abu-abu
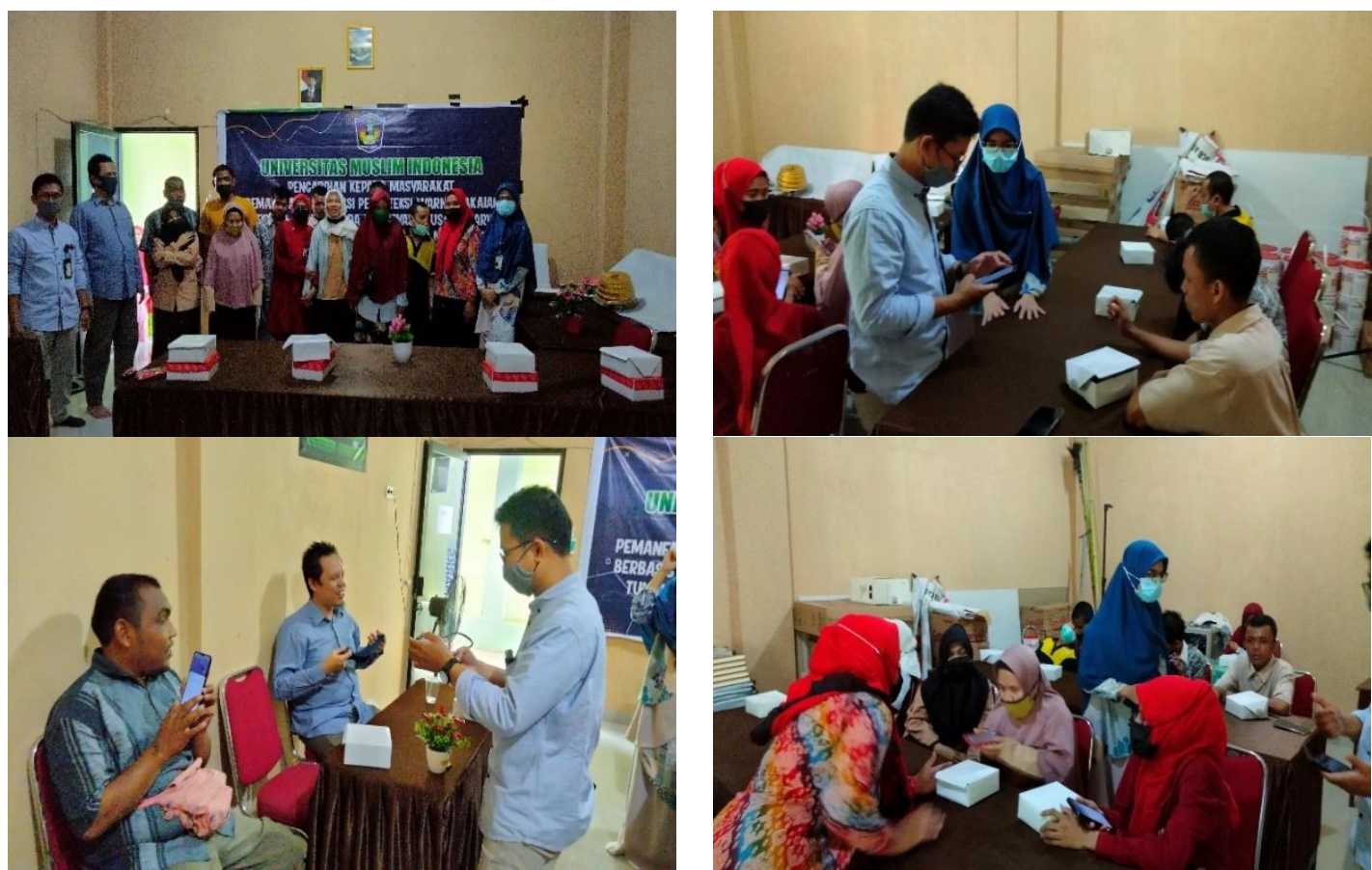

Gambar 3. Kegiatan sosialisasi aplikasi

Hasil akhir dari pelatihan ini adalah semua peserta yang terdiri dari beberapa guru dan siswa penyandang tunanetra mampu menggunakan aplikasi pendeteksi warna pakaian pada handphone masing-masing dan mampu mengenali warna pakaian yang dideteksi bedasarkan output berupa audio pada aplikasi. Beberapa peserta mudah memahami warna pakaian walaupun output aplikasi berupa audio warna pakaian menggunakan Bahasa Inggris dan terdapat 2 peserta yang kurang menangkap audio dari handphone karena keterbatasan sistem pendengarannya. Selain itu aplikasi yang dibangun hanya mampu menggunakan Bahasa Inggris dalam mengenali warna objek atau warna pakaian. Hal ini disebabkan oleh terbatasnya library yang digunakan dalam pemrograman android.

Pada akhir kegiatan, dilakukan evaluasi untuk mengetahui tingkat pemahaman peserta dalam mengoperasikan aplikasi dan tingkat kemampuan peserta dalam memahami output berupa audio dalam Bahasa Inggris yang menyebutkan warna pakaian atau objek yang tersorot dalam 
kamera. Berdasarkan hasil evaluasi, tingkat pemahaman peserta dalam mengoperasikan aplikasi pendeteksi warna pakaian melalui handphone adalah 100\% dan tingkat kemampuan peserta dalam memahami Bahasa Inggris adalah 98\% karena peserta merupakan siswa tingkat SMA dan guru SMA. Persentase evaluasi kegiatan diperoleh dari kuisioner yang diisi oleh tim pelaksana kegiatan dimana tim pelaksana menanyakan ke setiap peserta terkait aplikasi yang digunakan. Selain itu kuisioner diisi oleh tim pelaksana karena keterbatasan yang dimiliki peserta.

Pada akhir kegiatan juga dilakukan dilakukan review pelaksanaan kegiatan. Hasil review menujukkan bahwa kegiatan berjalan dengan lancar dan peserta sangat antusias dan bersemangat selama mengikuti kegiatan sosialisasi tersebut dengan membawa smartphone masing-masing.

\section{KESIMPULAN}

Pelaksanaan sosialisasi pemanfaatan aplikasi pendeteksi warna pakaian pada penyandang tunanetra di SLB Yukartuni Makassar berjalan dengan lancar dan tertib. Para peserta yang terdiri dari guru dan siswa sangat antusias dalam mengikuti seluruh rangkaian kegiatan. Peserta mampu mengoperasikan aplikasi dengan baik. Peserta mampu menangkap informasi warna pakaian melalui audio walaupun menggunakan Bahasa Inggris. Hal tersebut dikarenakan peserta merupakan guru dan siswa tingkat SMA sehingga dapat mengerti warna-warna dalam Bahasa Inggris. Aplikasi yang dimanfaatkan dapat memberikan kontribusi bagi peserta dalam mengenali warna objek terutama warna pakaian. Setelah mengikuti rangkaian kegiatan sosialisasi pemanfaatan aplikasi pendeteksi warna pakaian, diharapkan dapat melatih kemandirian peserta untuk memilih warna pakaian yang akan digunakan ke sekolah sehingga tidak keliru dalam menggunakan seragam sekolah.

\section{UCAPAN TERIMA KASIH}

Penulis mengucapkan terima kasih kepada civitas akademik SLB Yukartuni Makassar yang telah bersedia bekarjasama dan menjadi mitra pada kegiatan pengabdian kepada masyarakat.

\section{DAFTAR PUSTAKA}

Nurazizah, E., Ramdhani, M., \& Rizal, A. (2017). Rancang Bangun Termometer Digital Berbasis Sensor Ds18b20 Untuk Penyandang Tunanetra. eProceedings of Engineering 4(3), 3294-3301. https://openlibrarypublications.telkomuniversity.ac.id/index.php/engineering/article/vie $\mathrm{w} / 4858 / 4812$

Indriastuti, F., \& Saksono, W. T. (2018). Adaptasi Teknologi Qr Code Audio Pada Torso Biologi Untuk Siswa Tunanetra. Kwangsan: Jurnal Teknologi Pendidikan, 6(2), 137-155. https://doi.org/10.31800/jtp.kw.v6n2.p137--155

Jafar, A., Kadafi, A., \& Utaminingrum, F. (2018). Deteksi Objek Penghalang Secara Real-Time Berbasis Mobile Bagi Penyandang Tunanetra Menggunakan Analisis Blob. Jurnal Pengembangan Teknologi Informasi Dan Ilmu Komputer, 2(1), 423-432.

Kurniawan, I. H., \& Retnowati, N. D. (2018). Pengenalan Warna Berbasis Android Menggunakan Metode Template Matching. Compiler, 7(1), 29-36. https://doi.org/10.28989/compiler.v7i1.278

Maslahah, S., \& Suharmini, T. (2019). Pengaruh Aplikasi Color Detector for blind on based android (coda) terhadap pengenalan warna bagi penyandang tunanetra di yogyakarta. JPK (Jurnal Pendidikan Khusus), 14(1), 35-45. https://doi.org/10.21831/jpk.v14i1.25165

Mukmin, M., Suryawan, M. A., Ardiansyah, S., Teknik, D., Unidayan, I., \& Dayanu, J. (2019). Penerapan Ubiquitious Sistem Augmented Reality Untuk Mendeteksi Warna Obyek Berbasis Android. 124, 178-187. 


\section{Halaman Ini Dikosongkan}

